\title{
Heat Shock Protein 70 (HSP70) induces cytotoxicity of T-helper
} cells

\author{
C Figueiredo*1, M Wittmann², D Wang ${ }^{2}$, R Dressel ${ }^{3}$, R Blasczyk ${ }^{1}$ and B Eiz- \\ Vesper $^{1}$
}

Address: ${ }^{1}$ Institute for Transfusion Medicine, Hannover Medical School, Hannover, Germany, ${ }^{2}$ Department of Dermatology and Allergology, Hannover Medical School, Hannover, Germany and '3Department of Cellular and Molecular Immunology, University of Göttingen, Götttingen, Germany

* Corresponding author

from 12th Joint Meeting of the Signal Transduction Society (STS). Signal Transduction: Receptors, Mediators and Genes Weimar, Germany. 29-31 October 2008

Published: 26 February 2009

Cell Communication and Signaling 2009, 7(Suppl I):A28 doi:I0.II86/I478-8IIX-7-SI-A28

This abstract is available from: http://www.biosignaling.com/content/7/SI/A28

(c) 2009 Figueiredo et al; licensee BioMed Central Ltd.

Stress-inducible heat shock protein 70 (HSP70) has gained plenty of attention because of its potent adjuvant capability to induce antigen-specific $\mathrm{CD}^{+}$cytotoxic Tlymphocyte (CTL) and CD4+ T-helper cell (Th1) responses. In this study, we investigated the behavior of Tcell subsets stimulated with endotoxin-free recombinant HSP70 with respect to proliferation, cytokine expression, cytotoxicity against allogeneic B-lymphoblastoid cell line (B-LCL) and K562 cells as well as target-independent cytotoxicity.

$\mathrm{CD} 4{ }^{+}$cells exhibited a strong increase in proliferation after stimulation with HSP70, with rates of up to $29 \%$. In the presence of target cells, a 35 -fold up-regulation of granzyme B mRNA was observed after stimulation of CD4 ${ }^{+}$T-helper cells with HSP70 in combination with IL$7,-12$ and -15 . The target cell-independent secretion of granzyme $\mathrm{B}$ by $\mathrm{CD} 4^{+}$cells was greatly augmented after stimulation with HSP70 plus IL-2 or IL-7, -12 and -15.

In this study, we have shown that HSP70 is capable of inducing a cytotoxic response of T-helper cells in the absence of LPS or any other PAMPs. The granzyme B secretion and the cytolytic activity of CD4+ $\mathrm{T}$ cells is induced in a target-independent way, whereas the cytotoxic activity of $\mathrm{CD}^{+}$and $\mathrm{CD}^{+} \mathrm{T}$ cells can be further enhanced in the presence of the target cells. Our data provide novel insights into the role of extracellular HSP70 on T-cell immune response concerning the induction of targetindependent T-helper cell cytotoxicity. 